\title{
Prevention of stricture development after corrosive esophageal burn with a modified esophageal stent in dogs
}

\author{
Jing-Hai Zhou, MD, Yao-Guang Jiang, MD, Ru-Wen Wang, MD, Shi-Zhi Fan, MD, Tai-Qian Gong, PhD, Qun-You Tan, PhD, \\ Zheng Ma, PhD, Yun-Ping Zhao, PhD, and Bo Deng, MD
}

\begin{abstract}
Objective: We sought to test the feasibility and technical ease of a newly designed nitinol-based modified esophageal stent and its effects on preventing postcaustic stricture in mongrel dogs and to try to explain the result at the molecular level.
\end{abstract}

\begin{abstract}
Methods: Twenty-four dogs were included in this controlled study. Stenosis index (wall thickness/intraluminal diameter), pathologic features, hydroxyproline quantities, esophageal compliance, and biomechanics were compared between the injured but unstented and stented dogs. Transforming growth factor $\beta 1, \mathrm{Sma} / \mathrm{Mad}(\mathrm{Smad}) 3$, and Smad7 mRNA expression and protein levels in esophageal tissue were detected by means of reverse transcriptase-polymerase chain reaction and Western blotting, respectively.

Results: The modified esophageal stent was able to be placed and retrieved successfully and conveniently and was not only intact but there was also no macroscopic esophageal mucosal injury after the stent removal 4 months later. In comparison with the injured but unstented group, esophageal compliance, biomechanics, and the stenosis index were significantly better in the stented group. Histopathologic study revealed that collagen bundles were thinner and its orientation tended toward a regular and parallel pattern. Transforming growth factor $\beta 1$ and Smad3 mRNA expression and protein levels increased and Smad7 mRNA expression and protein levels decreased significantly in esophageal tissue in the stented group. These variables showed no statistically significant difference 2 months after stent removal.
\end{abstract}

Conclusions: The modified esophageal stent might be a promising stent in preventing stricture formation after corrosive esophageal burns clinically.

Supplemental material is available online.

Management of esophageal stricture, which has been one of the serious late complications after corrosive esophageal burns, is tricky and expensive. Therefore prevention of stricture formation is indispensable and cost-effective at the early phase after caustic agent ingestion. ${ }^{1-3}$ Among the currently preventive modalities, including neutralization of caustic agent, corticosteroids, antibiotics, and dilation, intraluminal esophageal stenting is one of the most effective therapies. ${ }^{4}$ However, nearly all of the stents used to prevent stricture formation after corrosive esophageal burns are constructed of medical silicone tubing and have the drawback of being readily obstructive, and the patient who has undergone esophageal intraluminal stenting can only eat liquid or semiliquid food. ${ }^{5,6}$

From the Department of Thoracic Surgery, Daping Hospital, Third Military Medical University, Chongqing, China.

Received for publication Aug 18, 2007; revisions received Dec 8, 2007; accepted for publication Feb 12, 2008.

Address for reprints: Yao-Guang Jiang, MD, Department of Thoracic Surgery, Daping Hospital, Third Military Medical University, Chongqing 400042, China (E-mail: zhzhlu1993@yahoo.com.cn).

J Thorac Cardiovasc Surg 2008; 136:1336-42

$0022-5223 / \$ 34.00$

Copyright (c) 2008 by The American Association for Thoracic Surgery doi:10.1016/j.jtcvs.2008.02.086
Expandable metallic stents have become popular for the treatment of malignant esophageal strictures in recent years. Although they are undoubtedly of great value in the palliation of nonoperable advanced esophageal cancers, there is concern over their use for the treatment of benign diseases. This is because stent removal is challengeable and might be hazardous because of the intense fibrotic reaction induced by the stent. ${ }^{7,8}$ Although some authors ${ }^{9,10}$ reported that some metal stents were extracted without surgical intervention, they were only able to remove one that had been placed less than 1 month prior, even within 1 week. However, it has been known that esophageal stents should be kept in place for several months if they prevent postcaustic stricture formation effectively. ${ }^{3}$

We modified the metallic stents (modified esophageal stent [MES]) based on the covered expandable nitinol stent available (Beijing Grikin Advanced Materials Co Ltd) so that the MES could be removed 4 months after placement. The purpose of this study was to test the feasibility and technical ease of MES and its effects on preventing postcaustic esophageal stricture in mongrel dogs. We also attempt to provide some insight as to the pathophysiology of the findings noted with the stent and extend our observations in an effort to explain such findings at the molecular level.

\section{MATERIALS AND METHODS}

Five knowledgeable professors had been invited to review the study, including how to treat the animals humanely, before the experiment started. 


\section{Abbreviations and Acronyms}

MES = modified esophageal stent

$\mathrm{PCR}=$ polymerase chain reaction

TGF- $\beta 1=$ transforming growth factor $\beta 1$

After ethics committee approval of the protocol, a preliminary experiment had been conducted to standardize the experimental model and the procedure for MES placement and removal. All the experimental procedures were performed in light of the "Management details on animals in medical experiments" of the National Health Ministry (1998).

\section{Animal Model}

The dogs were housed in indoor runs and fed at our experimental animal center and were cared for by an experienced animal handler under the supervision of an administrator in animal specialty. After overnight fasting, each dog was weighed and anesthetized with intramuscular injection of Sumianxin II $(0.2 \mathrm{~mL} / \mathrm{kg}$; Changchun Agricultural Pastoral University), a combination of xylazole, ethylenediamine tetra-acetic acid, dihydroetorphine hydrochloride, and haloperidol. The dogs were closely monitored, and a heating pad was used to maintain body temperature during the procedure. The length from the cuspid to the thoracic esophagus was measured, and a guide wire was placed during endoscopic guidance. Two $16 \mathrm{~F}$ Foley catheters sheathed the guide wire and were inserted into the thoracic esophagus in tandem. The distance between the catheters was adjusted to $10 \mathrm{~cm}$ away after the guide wire withdrawal. Ten milliliters of $10 \%$ $\mathrm{NaOH}$ solution was infused through the proximal catheter and left in place for 1 minute. Then the solution was aspirated with an injector, and $20 \mathrm{~mL}$ of saline was used to lavage the injured area 3 times. Rigid endoscopy was performed to confirm the degree of injury 24 hours later. Dogs were allowed to eat liquid 3 days after the injury. Any medication, including steroids, antibiotics, and proton pump inhibitors, that might have an influence on the esophageal stricture formation were not administered in the wake of caustic injury, but fluid was transfused until the dogs had a normal intake of fluid food after the procedure. Antalgics were administered once daily for the first 3 postoperative days. The dogs were examined twice daily for the first 7 postoperative days and once daily thereafter. The animals were observed for signs of pain, distress, fever, and melena. All the animals were weighed every month, and nutrition was maintained intravenously if they lost more than $30 \%$ of initial weight. The animal's digestive manifestations and mortalities were noted during the observation period.

\section{MES}

Design. Our MES had the following characteristics: (1) the MES was 16 $\mathrm{cm}$ in length and $2 \mathrm{~cm}$ in diameter; (2) silicone coating of $1 \mathrm{~cm}$ beyond the upper metal cage was affixed to the inside and outside of the stent; (3) a piece of nitinol string of $0.5 \mathrm{~mm}$ in diameter and $50 \mathrm{~cm}$ in length transfixed the upper metal circumference of MES; and (4) plastic valves were attached to the lower end of the MES (Figure 1).

MES placement. The MES was inserted into the canine esophagus 2 weeks after corrosive injury by using a delivery system during endoscopic guidance. After the stent was deployed, the delivery system and the tip of the MES string were brought out of the oral cavity. Esophagoscopy was again performed to verify the ideal position of the MES, which was located 2 to $4 \mathrm{~cm}$ beyond the proximal and distal borderline of the esophageal lesion. Finally, the proximal part of the nitinol string was sheathed in a $10 \mathrm{~F}$ catheter and penetrated out of the pharynx and subsequently secured on the neck.

MES removal. The MES was removed after 4 months. A $16 \mathrm{~F}$ Foley catheter was placed at the proximal end of the MES during endoscopic guidance, and $100 \mathrm{~mL}$ of icy saline was administered while the dog was kept in

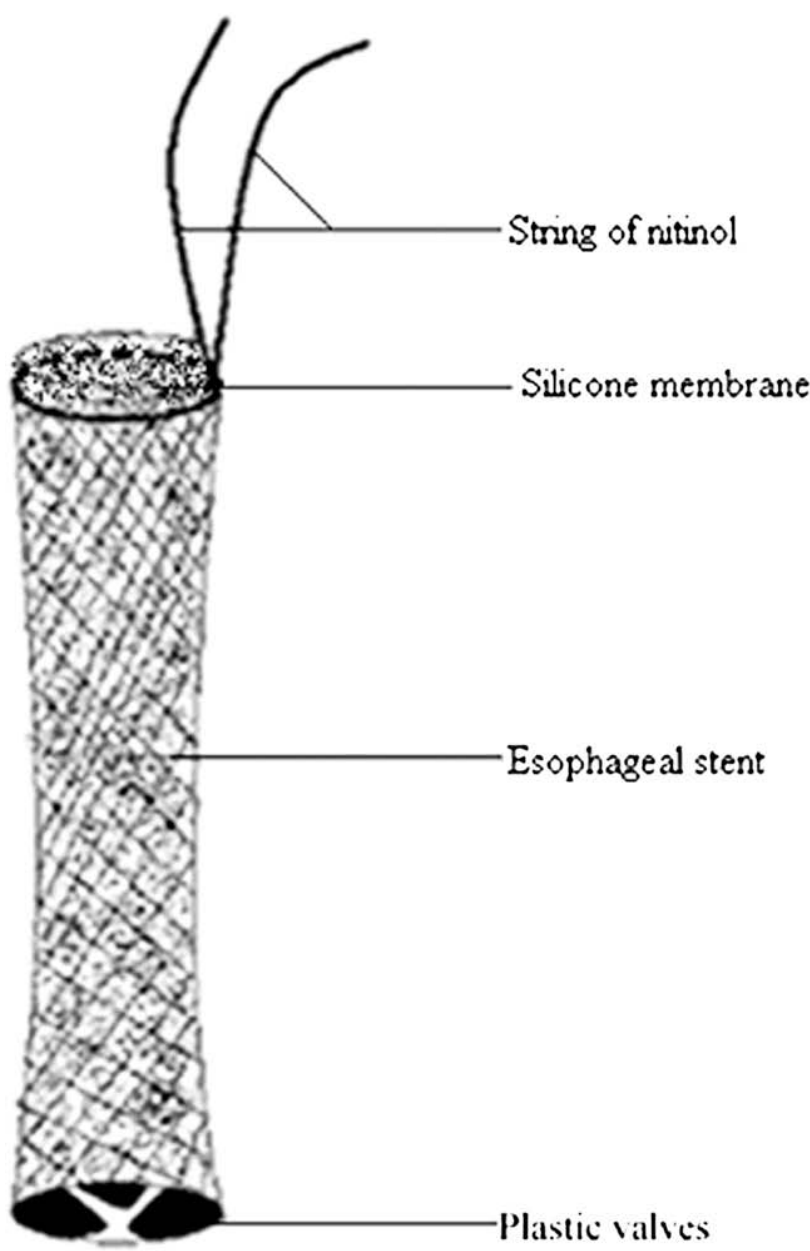

FIGURE 1. Schematic diagram of a modified esophageal stent. A long piece of nitinol string transfixed the upper metal circumference of the modified esophageal stent. Silicone membrane exceeding the upper metal cage by $1 \mathrm{~cm}$ was affixed to the inside and outside of the stent. Plastic valves were attached to the lower end of the modified esophageal stent.

a semi-Fowler's position (with head and thorax at $45^{\circ}$ elevation). The MES string was replaced into the pharynx and brought out of the oral cavity. A rigid esophagoscope was passed over the MES string before it was inserted into the esophagus. The MES string was continuously pulled while the endoscope was continuously advanced until the whole MES entered it. Then the endoscope was moved backward gradually, and the MES was removed simultaneously. The MES was detected carefully, if it was still intact. Finally, endoscopy was again performed to observe whether the esophagus had stricture, ulcer, bleeding, or perforation.

\section{Experimental Groups}

Four randomized groups, each of 6 mongrel dogs, were included in this study. Group A $(n=6)$, the control animals, were uninjured and untreated Group B $(n=6)$ had untreated esophageal burns and were humanely killed with $190 \mathrm{mg} / \mathrm{kg}$ pentobarbital sodium by means of intravenous injection 4.5 months after the injury if they still survived. The other dogs, which had been subjected to corrosive esophageal burns and treated with MESs 2 weeks after injury and had the MESs removed 4 months later, were divided into 2 groups according to the observation period after MES withdrawal. The dogs in group $\mathrm{C}(\mathrm{n}=6)$ were killed immediately after the MES removal, 
and the dogs in group $\mathrm{D}(\mathrm{n}=6)$ were killed after an additional 2 months of observation after the MES withdrawal.

\section{Pathologic Study and Sample Storage}

Animals dying in the late phase or being killed at the end of the experiment were weighed before autopsy. After the esophagus was harvested, the distal end of the injured area was ligated, and its proximal end was connected to a 3-way stopcock, which one way linked with a barometer and the third way attached to a $50-\mathrm{mL}$ injecting syringe to detect esophageal compliance, which was expressed by the ratio of esophageal pressure to the injected water (in centimeters of $\mathrm{H}_{2} \mathrm{O} /$ per milliliter). Then the injured esophagus was opened longitudinally, maximum esophageal wall thickness and minimum intraluminal diameter were assessed, and stenosis index (wall thickness/intraluminal diameter) was calculated subsequently. The maximum esophageal wall was selected for histologic sectioning. A part of each specimen was fixed in $4 \%$ paraformaldehyde and dehydrated, cleared, infiltrated, and embedded in paraffin. Four slides, each 4 to $6 \mu \mathrm{m}$ in thickness, were stained with hematoxylin and eosin. The other fraction of tissues in groups B and D were fixed in $2 \%$ glutaraldehyde for ultrastructure study. The remaining tissues were frozen with liquid nitrogen and kept at $-70^{\circ} \mathrm{C}$ to determine hydroxyproline quantities and transforming growth factor $\beta 1$ (TGF- $\beta 1$ ), Smad3, and Smad7 mRNA expression and protein levels and to detect esophageal biomechanics.

\section{Hydroxyproline Quantity Assay}

Hydroxyproline content of the esophageal tissue was determined according to the modified methods described by Reddy and Enwemeka. ${ }^{11}$ Fifty to eighty milligrams of esophageal tissues that had been thawed were hydrolyzed, oxidized, and vortexed. Then the optical densities of color samples were read with a spectrophotometer at $550 \mathrm{~nm}$. Hydroxyproline concentrations were calculated by means of a standard curve with standard solutions. The hydroxyproline content was expressed as micrograms per milligram of tissue.

\section{Detection of Esophageal Biomechanics}

An Instron tensile strength tester controlled by a computer was applied to investigate biomechanics of the samples. The esophageal tissues were fastened between the 2 grips, which were $5 \mathrm{~cm}$ away from each other, in the machine. The specimen was fixed relative to the lower clips and then subjected to a tensile load as the upper clips moved upward. Preliminary loading was performed 3 times so that the entire sample experienced a homogenous tension while testing. Fifteen millimeters per minute at velocity, 0.01 MegaPascal (MP) in fixed load, and 30\% of extension of the samples were set up, and esophageal biomechanics, including maximum load, elastic module, yield strength, intensive strengths, rupture intensity, applied strength, stretch rate at rupture, and stretch rate at definite force, were demonstrated on the computer while the specimen was extending.

\section{Reverse transcriptase-polymerase chain reaction}

Reverse transcriptase-polymerase chain reaction (PCR) was used to analyze TGF- $\beta 1$, Smad3, and Smad7 mRNA expression in esophageal tissue in dogs. Total RNA was extracted from each of the esophageal tissues with Tripure reagent (Roche), according to the manufacturer's instructions. For amplification of the desired cDNA, the following gene-specific primers were used, ${ }^{12-14}$ and $\beta$-actin was measured as an internal control: TGF- $\beta 1$ (151 bp), upstream $5^{\prime}$-CAAAGACTTTTCCCCAGACCTC- $3^{\prime}$ and downstream $5^{\prime}$ GGGTGGTCTTGAATAGGGGATC-3'; Smad3 (188 bp), upstream 5'-CCA GAGAGTAGAGACACCAGTTC- $3^{\prime}$ and downstream 5'-CTCCATCTT CACTCAGGTAGCC-3'; Smad7 (179 bp), upstream 5'-GATGGATTTTCT CAAACCAACTGC- $3^{\prime}$ and downstream $5^{\prime}$-TCCCCACTCTCGTCTTCTCC$3^{\prime}$; and $\beta$-actin (309 bp), upstream $5^{\prime}$-TCCCTCAAGATTGTCAGCAA- $3^{\prime}$ and downstream $5^{\prime}$-AGATCCACAACGGATACATT- ${ }^{\prime}$. Nested PCR reactions were all assembled in $25 \mu \mathrm{L}$ containing cDNA, $\mathrm{MgCl}_{2}$, primers, and Taq DNA polymerase. Samples were amplified for 27 cycles in a gradient PCR machine (Eppendorf) at denaturation $\left(95^{\circ} \mathrm{C}\right.$ for 1 minute for TGF- $\beta 1$ and $\mathrm{Smad} 3$ or $94^{\circ} \mathrm{C}$ for 1 minute for Smad7), annealing $\left(58^{\circ} \mathrm{C}\right.$ for 55 seconds for TGF- $\beta 1$ or $56^{\circ} \mathrm{C}$ for 55 seconds for Smad 3 and Smad7), and extension $\left(72^{\circ} \mathrm{C}\right.$ for 40 seconds for TGF- $\beta 1$ or $72^{\circ} \mathrm{C}$ for 1 minute for $\mathrm{Smad} 3$ and Smad7). The PCR products were electrophoresed on $1.5 \%$ agarose gels, stained with ethidium bromide, and observed with UV transillumination (Beckman). Intensity of the scanned image was determined with image analysis software (UVP) and was expressed by the number of white pixel areas. Results were calculated as a ratio of intensity of the specimen to the control gene $\beta$-actin.

\section{Western Blotting}

Western blotting was used for the measurement of TGF- $\beta 1$, Smad3, and Smad7 protein levels in esophageal tissues in experimental animals. Protein extract was separated by using $10 \%$ sodium dodecylsulfate-polyacrylamide gel electrophoresis and transferred to polyvinylidene difluoride membranes. After being blocked with $6 \%$ skim milk, the membranes were probed with rabbit anti-TGF- $\beta 1$, goat anti-Smad3, or goat anti-Smad7 antibodies (Santa Cruz Biotechnology) at a dilution of 1:2000 for 1 hour, followed by a 1-hour incubation with secondary anti-rabbit or anti-goat horseradish peroxidase-conjugated antibody (1:5000). Then a chemiluminescence signal was produced (DuPont) and captured on x-ray film. The results were expressed as a ratio of specimen Optical Density (OD) to samples in group A, which was as used the control arbitrarily.

\section{Statistical Analysis}

Data are expressed as medians with interquartile ranges. Statistical analysis was performed by using 1-way analysis of variance with SPSS 10.0 for windows (SPSS, Inc).

\section{RESULTS \\ Clinical Behavior}

Second- or third-degree injury was confirmed, and the length of the diseased esophagus was similar among groups $\mathrm{B}, \mathrm{C}$, and D by means of esophagoscopy, which was performed 24 hours after lye contact. One dog that died of esophageal perforation and acute mediastinitis within 24 hours after injury was excluded in group B. The remaining dogs in this group had dysphagia followed by regurgitation and cachexia since 3 weeks after the burns. Three animals died of malnutrition during the second month after injury, and the other animal died 1 month later, even when nutrition was maintained intravenously. Only 1 dog with untreated burns survived at the end of the observation period. As for the dogs being treated with the MES in the wake of lye ingestion, animals had anorexia in the first week after stent placement but had ravenous appetites 2 weeks later. All dogs had been able to eat a soft diet 3 weeks after MES use. The MES was removed successfully and conveniently 4 months after placement. All the extracted MESs were intact, and there were no blood blots or esophageal tissues on the outside of the MESs in groups C and D (Figure E1).

\section{Weight}

All 23 dogs were weighed after death or before being killed. The eventual weights of the dogs in group B were significantly less in comparison with their initial ones or the 
TABLE 1. Experimental results in esophageal tissues in dogs

\begin{tabular}{llcr}
\hline Group (n) & Stenosis index* & Hydroxyproline $(\boldsymbol{\mu} \mathbf{g} / \mathbf{m g})$ & $\begin{array}{c}\text { Compliance } \\
(\mathbf{c m ~ H} \mathbf{~} \mathbf{O} / \mathbf{m L})\end{array}$ \\
\hline A (6) & $0.072(0.050-0.099)$ & $0.350(0.309-0.463)$ & $4.80(4.38-4.93)$ \\
B (5) & $0.400(0.321-0.481) \dagger$ & $0.895(0.785-1.131) \dagger$ & $0.60(0.40-0.70) \dagger$ \\
C (6) & $0.053(0.048-0.095)$ & $0.429(0.282-0.516)$ & $3.30(2.83-4.10)$ \\
D (6) & $0.071(0.047-0.093)$ & $0.451(0.281-0.535)$ & $2.95(2.85-3.38)$ \\
\hline
\end{tabular}

Values are presented as medians (25th-75th interquartile ranges). $*$ Minimum intraluminal diameter (in millimeters)/maximum wall thickness (in millimeters). $\dagger P<.05$ compared with the remaining 3 groups.

postexperimental weights in the remaining groups. The dogs in groups $\mathrm{C}$ and $\mathrm{D}$ had no significant difference in weight between the pre-experimental and postexperimental periods (Table E1).

\section{Stenosis Index}

The esophageal stenosis index in group B increased significantly compared with that seen in groups $\mathrm{A}, \mathrm{C}$, and D. There was no significant difference among the latter 3 groups (Table 1).

\section{Histopothologic and Ultrastructural Findings}

After removing the MES and opening the esophagus longitudinally, there was no ulceration or bleeding in the intraluminal membrane in groups $\mathrm{C}$ and $\mathrm{D}$. Microscopic and ultrastructural findings in group B featured a large amount of collagen, which was arranged irregularly among fibroblast cells, and no inflammation was noted (Figures E2, A, and Figure E3, A). The collagen bundles were thinner, and their orientation tended toward regular and parallel patterns in groups $\mathrm{C}$ and $\mathrm{D}$ compared with those in group $\mathrm{B}$ (Figure E2, $B$, and Figure E3, $B$ ).

\section{Hydroxyproline Levels}

Hydroxyproline levels in esophageal tissue in group B were more than twice those in groups A, C, and D. There was no significant difference among hydroxyproline quantities in the latter 3 groups (Table 1).

\section{Esophageal Compliance}

Esophageal compliance in group B decreased significantly in comparison with that in groups $\mathrm{A}, \mathrm{C}$, and $\mathrm{D}$, but there was an insignificant difference in esophageal compliance in the latter 3 groups (Table 1).

\section{Esophageal Biomechanics}

In group B maximum load, elastic module, yield strength, intensive strength, rupture intensity, and applied strength increased while stretch rate at rupture and at definite force decreased significantly compared with those in groups A, C, and $\mathrm{D}$. There was no significant difference among esophageal biomechanics in the latter 3 groups (Table E2). The study revealed that elasticity improved and stiffness reduced in esophageal tissues in groups $\mathrm{C}$ and $\mathrm{D}$.

\section{TGF- $\beta 1$, Smad3, and Smad7 mRNA expression and protein levels}

In group B TGF- $\beta 1$ and Smad 3 mRNA expression and protein levels were higher and Smad7 mRNA and protein levels were significantly lower than those in groups A, C, and D (Tables 2 and 3 and Figures E4 and E5). Their differences were insignificant among the latter 3 groups. Dogs were taken in group B to compare the correlations among the TGF- $\beta 1$, Smad3, and Smad7 mRNA expression and protein levels. TGF- $\beta 1 \mathrm{mRNA}$ and protein levels had a positive correlation with $\mathrm{Smad} 3$ but a negative correlation with Smad7 (Tables 2 and 3).

\section{DISCUSSION}

Current coverable metallic stents, the efficacy of which has been well established in the treatment of malignant esophageal stricture and fistula, ${ }^{8}$ are impossible to use to prevent stricture formation after corrosive esophageal burns. It is well known that scar tissue progressively contracts several months after the start of the healing process after caustic agent ingestion. Four to 6 months is required to keep the esophageal stent in situ to prevent stricture formation. ${ }^{1,15}$ Fibrotic tissue, especially at the proximal and distal ends of the stent, cause the stent removal to be difficult, even

TABLE 2. TGF- $\beta 1$, Smad3, and Smad7 mRNA expression

\begin{tabular}{lllr}
\hline Group (n) & TGF- $\beta 1 / \beta$-actin $\dagger$ & Smad3/ $\beta$-actin & Smad7/ $\beta$-actin \\
\hline A (6) & $0.434(0.352-0.461)$ & $0.418(0.304-0.554)$ & $0.624(0.603-0.647)$ \\
B (5) & $1.326(1.179-1.352) \ddagger$ & $0.914(0.903-1.271) \ddagger$ & $0.269(0.245-0.321) \ddagger$ \\
C (6) & $0.461(0.383-0.312)^{*}$ & $0.515(0.458-0.578)^{*}$ & $0.834(0.626-1.252)$ \\
D (6) & $0.445(0.349-0.512)$ & $0.468(0.347-0.500)$ & $0.776(0.631-1.132)$ \\
\hline V
\end{tabular}

Values are presented as medians (25th-75th interquartile ranges). ${ }^{*} \mathrm{P}<.05$ compared with the remaining groups. $\dagger P<.05$, positive correlation with Smad3. $\ddagger P<.05$, negative correlation with Smad7. 
TABLE 3. TGF- $\beta 1$, Smad3, and Smad7 protein levels

\begin{tabular}{llll}
\hline Group (n) & TGF- $\beta$ 1/group A $\dagger$ & Smad3/group A & Smad7/group A \\
\hline A (6) & $1.000(1.000-1.000)$ & $1.000(1.000-1.000)$ & $1.000(1.000-1.000)$ \\
B (5) & $1.987(1.894-2.068) \ddagger$ & $2.717(2.138-3.031) \ddagger$ & $0.289(0.267-0.371) \ddagger$ \\
C (6) & $0.823(0.650-1.053) *$ & $1.049(0.979-1.109)^{*}$ & $0.974(0.961-1.040)$ \\
D (6) & $0.934(0.623-1.013)$ & $0.948(0.907-1.022)$ & $0.988(0.982-1.036)$ \\
\hline
\end{tabular}

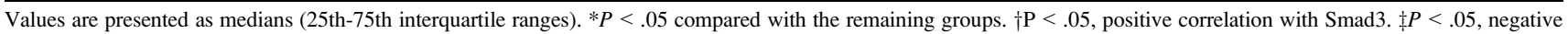
correlation with Smad7.

impossible, after several months of use. Most metal stents cannot be removed without surgical intervention. Moreover, long-term consequences of metal stent use can result in esophageal restenosis and rare but life-threatening complications, such as perforation and severe bleeding. ${ }^{8,16}$ Although some metal stents were extracted without surgical intervention, ${ }^{9,10}$ in these cases they were only able to remove the stents that had been in place for less than 1 month, even less than 1 week. Even though Song and colleagues ${ }^{17}$ constructed a special modified hook, they could only withdraw nitinol stents after 8 weeks of placement at best. Otherwise, the current stents are made of silicone and have the drawback of being obstructed easily. Therefore we modified the current covered expandable metal stent based on its pathophysiology after insertion to be used to prevent stricture formation after caustic esophageal burns.

The primary strategy for design of the MES is to prevent fibrotic tissue ingrowth and remove it conveniently. The features of the MES included the following. First, silicone coating of the inside and outside of the MES was thickened in an attempt to keep it intact 4 months after placement to eliminate hyperplastic tissue ingrowth through the mesh. Second, coating of $1 \mathrm{~cm}$ beyond the upper metal section of the MES was used to prevent tissue ingrowth at the proximal end of the MES. Third, plastic valves attached to the MES's lower end were used to obviate fibrotic tissue ingrowth at the distal end of the MES. Finally, the long nitinol string, which was sheathed in a $10 \mathrm{~F}$ catheter to forestall injury to the contiguous esophageal tissue, was used to pull up the MES for stent removal. In our study the MES was removed successfully and conveniently after 4 months. The silcone coating was intact, and there was no blood or esophageal tissue on the extracted MES. The results demonstrated that the MES had met all the conditions in the primary design.

As for the timing of stent placement after caustic ingestion, Motaf ${ }^{18}$ prefers 9 weeks after the injury rather than the early period. However, most authors ${ }^{3,4,19}$ stented the injured esophagus during the first 3 weeks and had successful results. We would like to insert the MES in the second week after caustic injury. This is because intense acute inflammatory reactions, including edema, cell necrosis, fatty saponification, blood vessel thrombosis followed by bacterial infiltration, and mucosal sloughing, developed within the first week of lye contact. Furthermore, experimental animals had anorexia at this time. Stenting might exacerbate the in- jury and predispose the animal to esophageal perforation at this time. One dog died of esophageal perforation after stenting during the first postcaustic week in our preliminary experiment. If the MESs were installed 3 weeks after the injury or since then, the injured animals began to have symptomatic strictures, and dilation can be required. During the second week after the burn, although synthesis, deposition, and remodeling of collagen became apparent, esophageal stricture still had not formed. ${ }^{1}$ That is the reason why all the MESs were installed during the second week of injury in this study. MES placement was successful, with no need for esophageal dilation in all 12 dogs.

Experimental and clinical evidence suggest that 4 factors, including the obliteration of esophageal lumen by edema and exuberant granulation tissue, adhesion between adjacent ulcerated areas, contraction of the fibrous scar formed in the esophageal wall, and destruction of the myenteric plexus, are responsible for the development of stricture after caustic esophageal injury. ${ }^{19}$ In the laboratory intraluminal splinting with an inert material, such as Silastic, reduced the amount of inflammation and granulation tissue and minimized scaring. In addition, having the stent in place prevented the fusion of mural ulcers and obliteration of the lumen by granulation tissue during the remodeling period of the cicatrized esophagus when it persisted for several months. ${ }^{4}$ MESs also performed a similar function. In this study most of the dogs (4/5) in group B had early and variable mortality before the experiment ended. This early mortality might have created a form of lead time bias. However, the esophageal pathophysiology in injured dogs was stricture formation of more than 3 weeks in the wake of injury. The first dog died 2 months after the injury. Even if all the dogs had survived the experiment, esophageal stricture would still be the main manifestation. Therefore group B was reported, and comparative analysis was conducted. Compared with dogs with untreated burns, the esophageal stenosis index and hydroxyproline quantities decreased significantly, the orientation of collagen tended toward a regular and parallel pattern, and the esophageal compliance and elasticity in biomechanics improved dramatically with MES placement after caustic esophageal burns. These variables showed no significant changes after 2 months in the wake of MES removal. MESs might decrease the synthesis and deposition of the collagen and regulate its arrangement to prevent stricture formation after corrosive injury in light 
of our experimental evidence. This is different from the clinical results in patients with advanced esophageal cancer, in which a metal stent induces the fibrotic reaction. ${ }^{8}$ Injured esophageal tissue and cancer cells might have different responses to the installed metal stent at the molecular level.

TGF- $\beta$ is a central mediator of wound healing and scaring processes throughout the body. The development of keloid and hypertrophic scarring and pulmonary, renal, and hepatic fibrosis are all involved with increased expression of TGF$\beta 1$. This is primarily because of TGF- $\beta 1$ promoting extracellular matrix production while simultaneously suppressing extracellular matrix proteolysis and breakdown. ${ }^{20}$ TGF- $\beta$ induces its type I and type II receptors to form heteromers in which the type II receptor phosphorylates and activates the type I receptor, which in turn activates cytoplasmic signaling mediators known as Smads. Among the 8 Smads that have been found in vertebrates, TGF- $\beta / \mathrm{Smad} 3$ might play a central role in specific pathologic fibrosis. ${ }^{21}$ However, Smad7, a natural antagonist of TGF- $\beta$ signaling, acts through Smad 3 receptor interactions and subsequent phosphorylation and by recruiting E3 ubiquitin ligases called Smad ubiquitin regulatory factor Smurf1 and Smurf2 to the receptor complexes, leading to the degradation of the latter. ${ }^{22}$ In this study, compared with the dogs with untreated esophageal burns, the dogs with MES treatment after injury had lower TGF- $\beta$ and Smad3 mRNA expression and protein levels and higher Smad7 mRNA expression and protein levels. It is suggested that TGF- $\beta 1$, Smad3, and Smad7 might contribute to one of the molecular mechanisms of MES preventing stricture formation after corrosive esophageal burns.

To our knowledge, the Alveolus stent (Alveolus, Inc) and Polyflex plastic stents (Rüsch) are presently available and in use successfully in benign disease. Both of them appear to be easy to insert and simple to remove (requiring only flexible endoscopy) and can be used to manage benign esophageal disease. However, the data on benign esophageal strictures have been mixed. Multicenter prospective studies are needed to evaluate the late complication rate and long-term effectiveness. ${ }^{23}$ Furthermore, stent migration might be their Achilles' heel. Baron and colleagues ${ }^{24}$ reported that 7 of 8 Alveolus esophageal stent displacements occurred in a porcine model. Siddiqui and coworkers ${ }^{25}$ showed that Polyflex silicone stents migrated into the stomach in $60 \%$ patients with esophageal stenosis, and there was no proximal migration. Other authors ${ }^{26}$ also concluded that stent migration was the most common long-term complication. Our stent has a piece of nitinol string of $0.5 \mathrm{~mm}$ in diameter and $50 \mathrm{~cm}$ in length transfixed to the upper metal circumference of the MES to keep it in place. Use of a string that penetrated the pharynx to retrieve the stent in human subjects might be possible because the string was sheathed in a $12 \mathrm{~F}$ catheter that had been used in patients with corrosive esophageal burns in our department. ${ }^{15}$ Moreover, plastic valves were attached to the lower end of the MES to decrease gastroesophageal reflux.
In conclusion, an animal model of esophageal stricture after corrosive esophageal burns with $\mathrm{NaOH}$ introduced in this study is an easily performed procedure. MESs can be removed successfully and conveniently after 4 months of placement and prevent esophageal stricture formation after caustic injury in mongrel dogs. MESs might be a promising stent in preventing the development of stricture in patients after serious corrosive esophageal burns and managing other benign stenoses after the lengths of MES and its string are adjusted in light of the esophageal lesion.

\section{References}

1. Ramasamy K, Gumaste VV. Corrosive ingestion in adults. J Clin Gastroenterol. 2003;37:119-24.

2. Adam JS, Birck HG. Pediatric caustic ingestion. Ann Otol Rhinol Laryngol. 1982 91:656-8.

3. Zhou JH, Jiang YG, Wang RW, Lin YD, Gong TQ, Zhao YP, et al. Managemen of corrosive esophageal burns in 149 cases. J Thorac Cardiovasc Surg. 2005;130 449-55.

4. Reyes HM, Hill JL. Modification of the experimental stent technique for esophageal burns. J Surg Res. 1976;20:65-70.

5. Berkovits RN, Bos CE, Wijburg FA, Holzki J. Caustic injury of the oesophagus. Sixteen years experience, and introduction of a new model oesophageal stent. J Laryngol Otol. 1996;110:1041-5.

6. Broto J, Asensio M, Vernet JM. Results of a new technique in the treatment of severe esophageal stenosis in children: Polyflex stents. J Pediatr Gastroenterol Nutr. 2003;37:203-6.

7. Ackroyd R, Watson DI, Devitt PG, Jamieson GG. Expandable metallic stents should not be used in the treatment of benign esophageal strictures. J Gastroenterol Hepatol. 2001;16:484-7.

8. Lee JG, Hsu R, Leung JW. Are self-expanding metal mesh stents useful in the treatment of benign esophageal stenoses and fistulas? An experience of four cases. Am J Gastroenterol. 2000;95:1920-5.

9. Zhang C, Yu JM, Fan GP, Shi CR, Yu SY, Wang HP, et al. The use of a retrievable self-expanding stent in treating childhood benign esophageal strictures. J Pediatr Surg. 2005;40:501-4

10. Cheng YS, Li MH, Chen WX, Chen NW, Zhuang QX, Shang KZ. Temporary partially-covered metal stent insertion in benign esophageal stricture. World J Gastroenterol. 2003;9:2359-61.

11. Reddy GK, Enwemeka SC. A simplified method for the analysis of hydroxyproline in biological tissue. Clin Biochem. 1996;29:225-9.

12. Katuri V, Tang Y, Marshall B, Rashid A, Jogunoori W, Volpe EA, et al. Inactivation of ELF/ TGF-beta signaling in human gastrointestinal cancer. Oncogene. 2005;24:8012-24.

13. Benus GF, Wierenga AT, de Gorter DJ, Schuringa JJ, van Bennekum AM, Drenth-Diephuis L, et al. Inhibition of the transforming growth factor beta (TGFbeta) pathway by interleukin-1beta is mediated through TGF beta-activated kinase 1 phosphorylation of SMAD3. Mol Biol Cell. 2005;16:3501-10.

14. Javelaud D, Delmas V, Moller M, Sextius P, Andre J, Menashi S, et al. Stable overexpression of Smad7 in Human melanoma cells inhibits their tumorigenicity in vitro and in vivo. Oncogene. 2005;24:7624-9.

15. Wang RW, Zhou JH, Jiang YG, Fan SZ, Gong TQ, Zhao YP, et al. Prevention of stricture with intraluminal stenting through laparotomy after corrosive esophageal burns. Eur J Cardiothorac Surg. 2006;30:207-11.

16. Hramiec JE, O'Shea MA, Quinlan RM. Expandable metallic esophagea stents in benign disease: a cause for concern. Surg Laparosc Endosc. 1998;8:40-3.

17. Song HY, Jung HY, Park SI, Chen NW, Zhuang QX, Shang KZ. Covered retrievable expandable nitinol stents in patients with benign esophageal strictures: initial experience. Radiology. 2000;217:551-7.

18. Mutaf $\mathrm{O}$. Treatment of corrosive esophageal strictures by long-term stenting. J Pediatr Surg. 1996;31:681-5.

19. Fell SC, Denize A, Becker EH. The effect of intraluminal splinting on the prevention of caustic stricture of the esophagus. J Thorac Cardiovasc Surg. 1966;52: 675-81.

20. Eickelberg O. Endless healing: TGF-beta, SMADs, fibrosis. FEBS Lett. 2001;506 $111-4$. 
21. Roberts AB, Tian F, Byfield SD, Stuelten C, Ooshima A, Saika S, et al. Smad3 is key to TGF- $\beta$-mediated epithelial-to-mesenchymal transition, fibrosis, tumor suppression and metastasis. Cytokine Growth Factor Rev. 2006;17: 19-27.

22. Schiller M, Javelaud D, Mauviel A. TGF- $\beta$-induced SMAD signaling and gene regulation: consequences for extracellular matrix remodeling and wound healing. J Dermatol Sci. 2004;35:83-92.

23. Papachristou GI, Baron TH. Use of stents in benign and malignant esophageal disease. Rev Gastroenterol Disord. 2007;7:74-88.
24. Baron TH, Burgart LJ, Pochron NL. An internally covered (lined) self-expanding metal esophageal stent: tissue response in a porcine model. Gastrointest Endosc. 2006;64:263-7.

25. Siddiqui AA, Loren D, Dudnick R, Kowalski T. Expandable polyester siliconcovered stent for malignant esophageal strictures before neoadjuvant chemoradiation: a pilot study. Dig Dis Sci. 2007;52:823-9.

26. Ott C, Ratiu N, Endlicher E, Rath HC, Gelbmann CM, Schölmerich J, et al. Selfexpanding Polyflex plastic stents in esophageal disease: various indications, complications, and outcomes. Surg Endosc. 2007;21:889-96. 


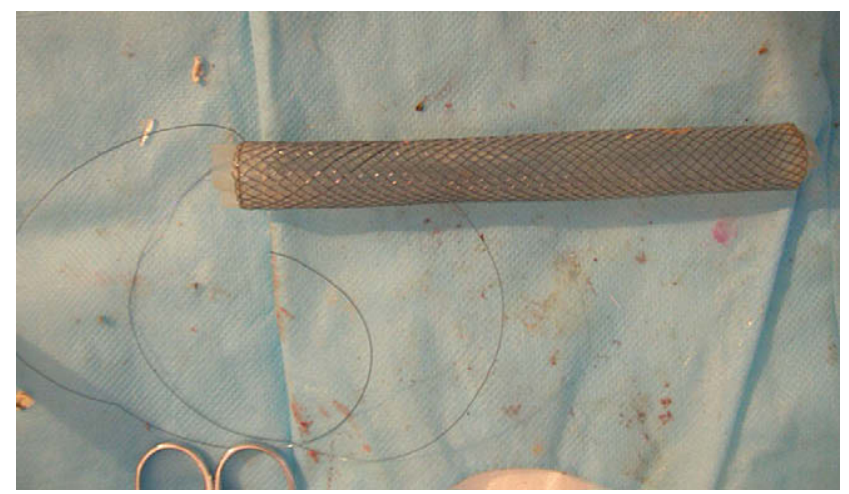

FIGURE E1. A modified esophageal stent that was removed from an animal in group D. 

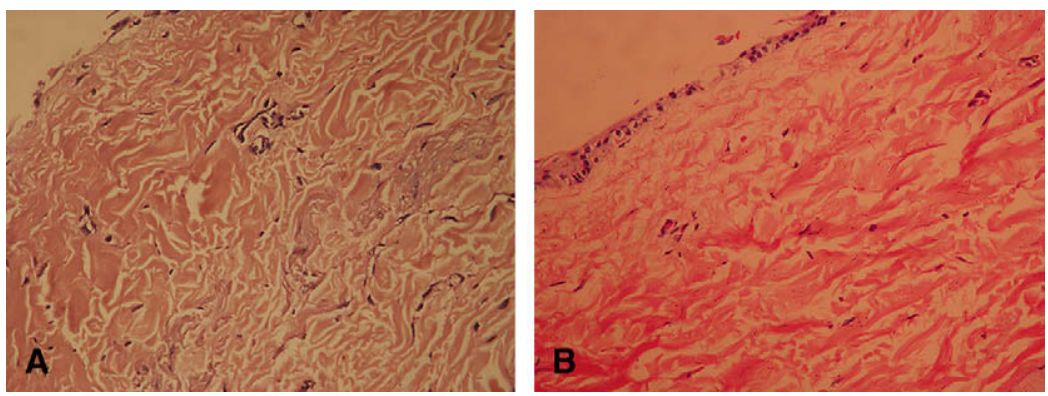

FIGURE E2. Light microscopic studies on the esophageal tissue in dogs. (Hematoxylin and eosin stain, original magnification 200×.) A, Fibroblast cells with a large amount of irregularly arranged collagen deposition in group B. B, Less fibroblast cells and collagen bundles with regular orientation in group D compared with those in group B. 


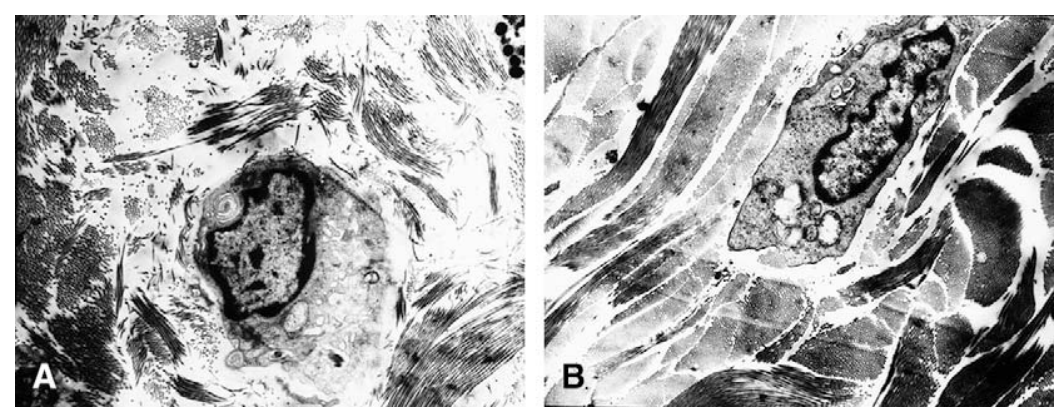

FIGURE E3. Transmission electron microscopic studies of the esophageal tissue in dogs. (Original magnification $4200 \times$.) A, Irregularly arranged collagen bundles in group B. B, Thinner collagen bundles with regular orientation in group D compared with those in group B. 

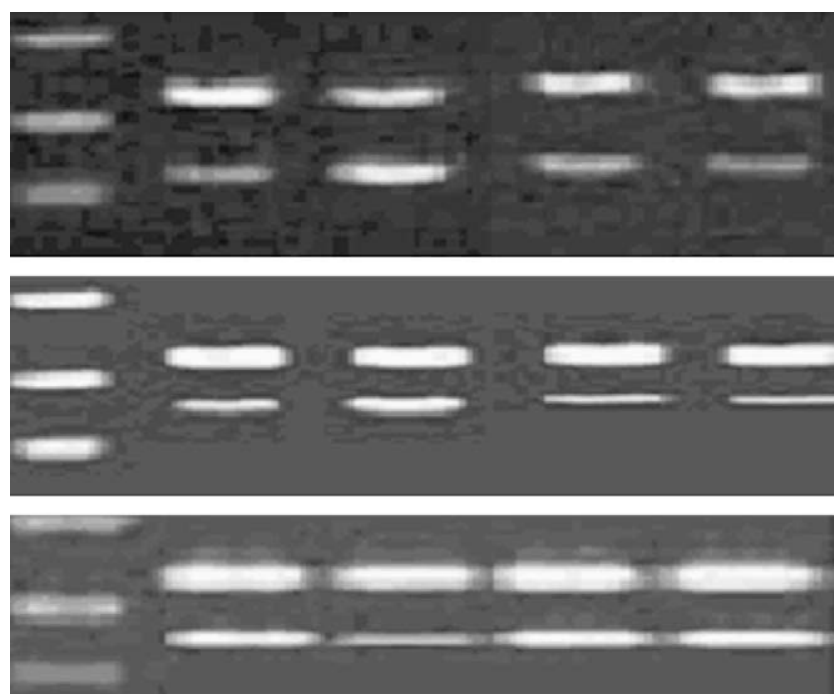

FIGURE E4. Reverse transcriptase-polymerase chain reaction showing of an electrophoretogram of TGF- $\beta 1$, Smad3, and Smad7 mRNA in esophageal tissue in dogs. TGF- $\beta 1$ and Smad3 levels decreased and Smad7 levels increased in the stented group compared with those in the untreated group. $\beta$-actin was used as the control gene. 

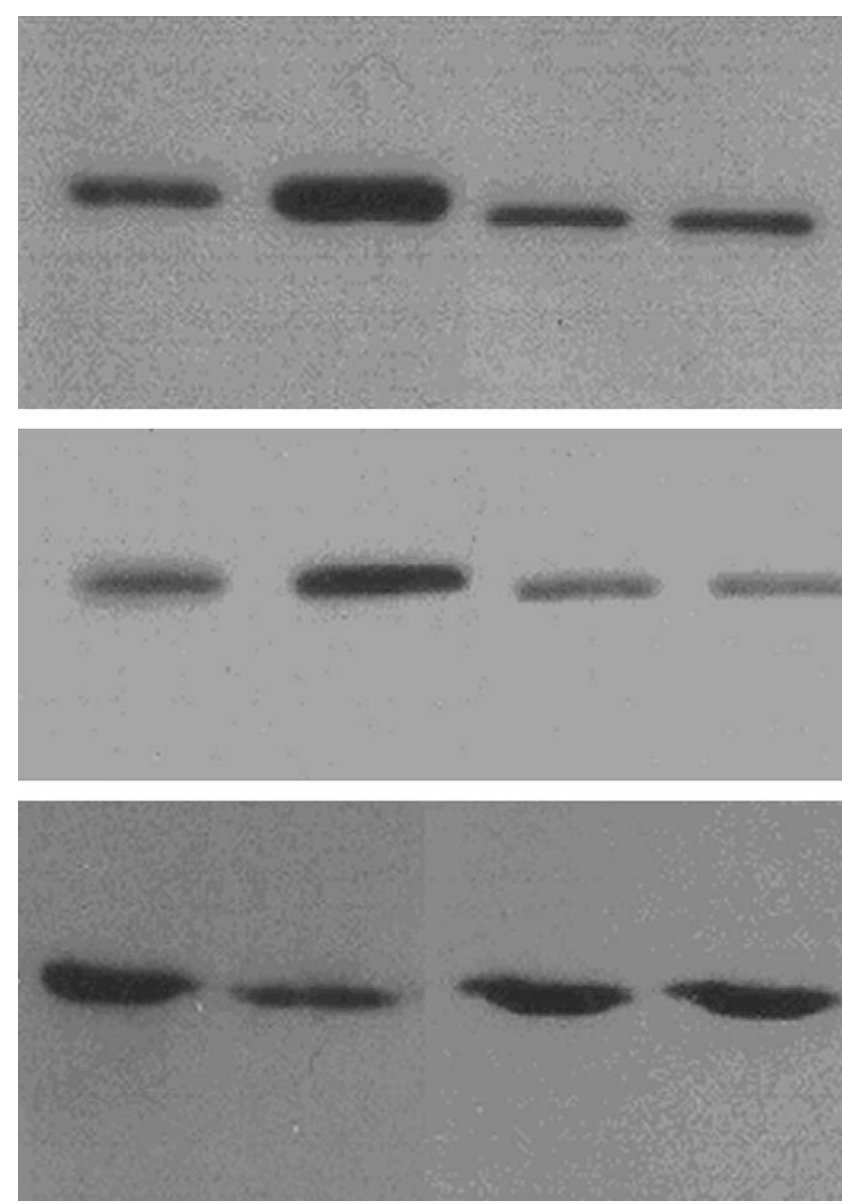

FIGURE E5. Western blot showing chemiluminescent film of TGF- $\beta 1$, Smad3, and Smad7 protein in esophageal tissue in dogs. TGF- $\beta 1$ and Smad 3 levels decreased and Smad7 levels increased in the stented group compared with those in the untreated group. 
TABLE E1. Comparison of pre-experimental and post-experimental canine weight

\begin{tabular}{lcrrr}
\hline & \multicolumn{2}{c}{ Before the experiment } & \multicolumn{2}{c}{ After the experiment } \\
\cline { 2 - 5 } Group & $\mathbf{n}$ & Weight $(\mathbf{k g})$ & $\mathbf{n}$ & Weight $(\mathbf{k g})$ \\
\hline A & 6 & $12.8(11.4-15.1)$ & 6 & $13.0(12.3-14.6)$ \\
B & 6 & $13.5(12.9-14.6)$ & 5 & $9.5(8.8-10.0)^{*} \dagger$ \\
C & 6 & $13.3(12.4-14.8)$ & 6 & $13.5(12.4-14.3)$ \\
D & 6 & $13.5(12.9-14.3)$ & 6 & $13.0(12.5-14.5)$ \\
\hline$P<.05$ compared with initial weight. $\dagger P<0.05$ compared with postexperimental weight in the remaining 3 groups. &
\end{tabular}


TABLE E2. Esophageal biomechanics in dogs

\begin{tabular}{|c|c|c|c|c|}
\hline \multirow[b]{2}{*}{ Biomechanics } & \multicolumn{4}{|c|}{ Group (n) } \\
\hline & A (6) & B (5) & $\mathrm{C}(6)$ & D (5) \\
\hline Maximum load & $27.4(19.8-32.1)$ & $65.4(52.0-80.1)^{*}$ & $23.4(19.6-29.8)$ & $25.7(19.8-32.9)$ \\
\hline Elastic module & $1.7(0.7-2.7)$ & $4.7(3.4-6.1)^{*}$ & $1.4(1.1-2.4)$ & $1.2(0.6-1.6)$ \\
\hline Yield strength & $1.1(0.3-2.2)$ & $3.3(3.0-4.5)^{*}$ & $1.1(0.8-2.0)$ & $0.89(0.4-1.0)$ \\
\hline Intensive strength & $1.1(0.4-1.5)$ & $4.6(3.6-5.0) * 1.7(0.9-2.5)$ & $1.2(0.8-1.9)$ & \\
\hline Rupture intensity & $0.8(0.3-1.1)$ & $3.0(1.7-3.5)^{*}$ & $0.7(0.6-1.4)$ & $0.7(0.2-1.2)$ \\
\hline Applied strength & $0.2(0.1-0.3)$ & $1.0(0.9-1.3)^{*}$ & $0.3(0.1-0.7)$ & $0.4(0.3-0.5)$ \\
\hline $\begin{array}{l}\text { Stretch rate } \\
\text { at rupture }\end{array}$ & $107.8(95.8-120.1)$ & $56.3(43.7-63.1)^{*}$ & $139.6(114.7-173.6)$ & $119.7(81.3-143.2)$ \\
\hline $\begin{array}{l}\text { Stretch rate } \\
\text { at definite force }\end{array}$ & $15.3(11.6-20.5)$ & $7.3(3.9-8.7)^{*}$ & $21.2(15.3-26.4)$ & $26.2(14.4-29.2)$ \\
\hline
\end{tabular}

$* P<.05$ compared with the remaining 3 groups. 